\title{
The role of photosensitized macrophages in photodynamic therapy
}

\author{
ALEKSANDRA KAWCZYK-KRUPKA ${ }^{1}$, ZENON CZUBA ${ }^{2}$, \\ EWELINA SZLISZKA ${ }^{2}$, WOJCIECH KRÓL ${ }^{2}$ and ALEKSANDER SIEROŃ ${ }^{1}$
}

\author{
${ }^{1}$ Center for Laser Diagnostics and Therapy, Department of Internal Diseases, Angiology and Physical Medicine of \\ the Chair of Internal Diseases Medical University of Silesia, Katowice, 15 Batory St., 41-902 Bytom; ${ }^{2}$ Department of \\ Microbiology and Immunology, Medical University of Silesia, Katowice, 19 Jordana St., 41-808 Zabrze, Poland
}

Received January 20, 2011; Accepted March 8, 2011

DOI: 10.3892/or.2011.1262

\begin{abstract}
Cancer stimulates macrophage infiltration and encourages angiogenesis, which is necessary for tumor growth and invasion. It seems, that the influence of photodynamic therapy (PDT) on immune cells and immune regulators plays a crucial role in this process. In order to study this effect, the influence of $\delta$-aminolevulinic acid (ALA) PDT on the activity of the murine macrophage J-774A.1 cell line was assessed. J-774A.1 cells were incubated with different concentrations of ALA and irradiated with a VIS light source $(400-750 \mathrm{~nm})$ at 5,10 and $30 \mathrm{~J} / \mathrm{cm}^{2}$. The effects of ALA-PDT were evaluated on the basis of cell viability and the secretory activity of macrophages (nitric oxide, NO; reactive oxygen intermediates, ROI; tumor necrosis factor $\alpha$, TNF- $\alpha$; interleukin-1 $\beta$, IL-1 $\beta$; and nuclear factor $\kappa \mathrm{B}, \mathrm{NF}-\kappa \mathrm{B}$; proteins, $\mathrm{p} 50$ and p65). Experiments showed that at the higher energy doses, there was a large increase in ROI and TNF- $\alpha$ release and decreased levels of NF- $\kappa B$ p50 and p65, IL- $1 \beta$ production and NO release. The increased levels of ROI and TNF- $\alpha$ release after PDT could be an additional factor for the complete eradication of tumors. The decrease in NF- $\kappa$ B p50 and p65 and IL-1 $\beta$ levels could inhibit tumor progression.
\end{abstract}

\section{Introduction}

Cancer elicits macrophage infiltration, stimulate angiogenesis (1) which is necessary for tumor expansion, provide growth factors for hematopoietic cells and for fibroblasts. The outcome of this fact is central to arguments concerning the

Correspondence to: Dr Aleksandra Kawczyk-Krupka, Center for Laser Diagnostics and Therapy, Department of Internal Diseases, Angiology and Physical Medicine of the Chair of Internal Diseases Medical University of Silesia, Katowice, 15 Batory St., 41-902 Bytom, Poland

E-mail: akawczyk@gmail.com

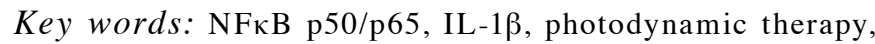
$\delta$-aminolevulinic acid, J-774A.1 cells, ROI, TNF- $\alpha$, NO, chemiluminescence role of macrophages in tumor incidence, growth and invasion. It seems, that influence of photodynamic therapy (PDT) on immune cells and immune regulators plays a crucial role in this process. PDT is a well-known method for the selective, non-invasive and effective treatment of precancerous and cancerous lesions due to the activation of photobiochemical processes that cause cytotoxicity (2). PDT is based on mutual reactions between laser irradiation and photosensitizers that accumulate in tissues and result in selective damage of pathological tissues (3).

The anticancer effect of PDT is due to three main mechanisms. First, PDT is cytotoxic, with both necrotic and apoptotic effects. Second, PDT leads to the occlusion of blood and lymphatic vessels of the tumor. Third, PDT is associated with the modulation of immune and inflammatory responses. It has been proven, that PDT causes acute inflammation, expression of heat-shock proteins, invasion and infiltration of the tumor by leukocytes, and might increase the presentation of tumor-derived antigens to T cells (4). Many studies have reported the infiltration of lymphocytes, neutrophils and macrophages into PDT-treated tissue, indicating activation of the immune response.

Necrosis of cancer cells and hypoxia leads to the activation of tumor-associated macrophages (TAMs). Monocytes/ macrophage progenitors, migrate to hypoxic sites, which in turn release growth, survival and angiogenic factors, such as tumor necrosis factor (TNF), interleukin-1 (IL-1), IL-6, CXC-chemokine ligand 8 (CXCL8), vascular endothelial growth factor and colony-stimulating factor 1, that support tumor promotion, growth and progression (5). Photodynamic activation of macrophage-like cells contributes to an effective outcome of PDT treatment. In order to gain information on the activation of macrophages during PDT, the influence of $\delta$-aminolevulinic acid (ALA) PDT on the viability and secretory activity was studied.

Inflammation seems to be an important tumor promoter and macrophages are important producers of cytokines and nitric oxide, and they are well suited for increasing tumor invasion and angiogenesis. Additionally, production of reactive nitrogen species (RNS) in response to induction of iNOS expression by transcription factor nuclear factor $\kappa \mathrm{B}(\mathrm{NF}-\mathrm{\kappa B})$ might lead to the generation and accumulation of additional DNA mutations that drive tumor progression. 
The transcription factor NF- $\mathrm{KB}$ and the classical signaling pathway that controls its activation have emerged as central components of inflammation and cancer. The I $\mathrm{K} B$ kinase (IKK)-NF- $\kappa B$ system can function in both the malignant component of the tumor, in which it provides the cells with resistance to apoptotic and genotoxic insults, and the inflammatory component, in which its activation leads to the production of growth factors that stimulate tumor growth and angiogenesis. It has been demonstrated that PDT stimulates macrophages, neutrophils and $\mathrm{T}$ lymphocytes to secrete cytokines (IL-6 and -10) and TNF- $\alpha$ (6).

PDT uses light-activated molecules that produce reactive oxygen intermediates (ROIs) and unwanted tissue destruction after illumination. During photodynamic action, NO is generated by macrophages and neutrophils as part of the human immune response and also contributes to vessel homeostasis by inhibiting vascular smooth muscle contraction and growth, platelet aggregation and leukocyte adhesion to the endothelium (7). Nitric oxide reacts with superoxide to produce peroxynitrite. Reactive oxygen species (ROS) is a collective term that broadly describes $\mathrm{O}_{2}$-derived free oxygen species, such as superoxide anion $\left(\mathrm{O}_{2}^{\bullet-}\right)$, hydroxyl $(\mathrm{HO} \bullet)$, peroxyl $\left(\mathrm{RO}_{2} \bullet\right)$, and alkoxyl $(\mathrm{RO} \bullet)$ radicals, and $\mathrm{O}_{2}$-derived nonradical compounds, such as hydrogen peroxide $\left(\mathrm{H}_{2} \mathrm{O}_{2}\right)(8)$. To evaluate the cytotoxicity of PDT on cell lines, experiments have been performed in L929 and MDPC-23 cell cultures with Photogem ${ }^{\circledR}$ associated with a blue light-emitting diode (LED) (9). These trials showed a predominance of necrotic cell death connected with high intracellular levels of ROS. More recent studies have shown that PDT can also be an effective alternative for antimicrobial treatment and is connected with a high level of reactive oxygen intermediates (10). Therefore, PDT has been proposed as a therapy for a large variety of localized infections $(11,12)$ and periodontal diseases $(13)$.

In the present study, the role of ALA-PDT in the immune response and the role of macrophages in the photodynamic action was assessed on the basis of cell viability and the production of nitric oxide, chemiluminescence, TNF, NF- $\mathrm{KB}$ proteins p50/p65 and IL-1ß.

\section{Materials and methods}

The murine macrophage cell line J-774 A.1. The murine macrophage cell line J-774A.1 was obtained from the German Collection of Microorganisms and Cell Cultures, Department of Human and Animal Cell Cultures, in Braunschweig (DSMZ, Germany) and cultured in Dulbecco's modified Eagle's medium (DMEM) containing 10\% heat-inactivated South American origin fetal bovine serum (FBS) containing $100 \mathrm{U} /$ $\mathrm{ml}$ penicillin and $100 \mu \mathrm{g} / \mathrm{ml}$ streptomycin (all obtained from Bio-Whittaker, Verviers, Belgium). The cells were grown and sub-cultured under standard conditions. J-774A.1 cells were grown in 48-well Nunclon polystyrene flat-bottom plates. Plates were incubated with different concentrations (125, 250,500 , and $1000 \mu \mathrm{M}$ ) of $\delta$-ALA (Medac GmbH, Wedel, Germany) for $4 \mathrm{~h}$ and then irradiated with VIS (Versatile Ion Source) $(400-750 \mathrm{~nm})$ at 5,10 and $30 \mathrm{~J} / \mathrm{cm}^{2}$ delivered from the incoherent light source PDT TP-1 (Cosmedico Medizintechnik GmbH, Schwenningen, Germany). Next, the cells were stimulated with lipopolysaccharide (LPS) $200 \mathrm{ng} /$

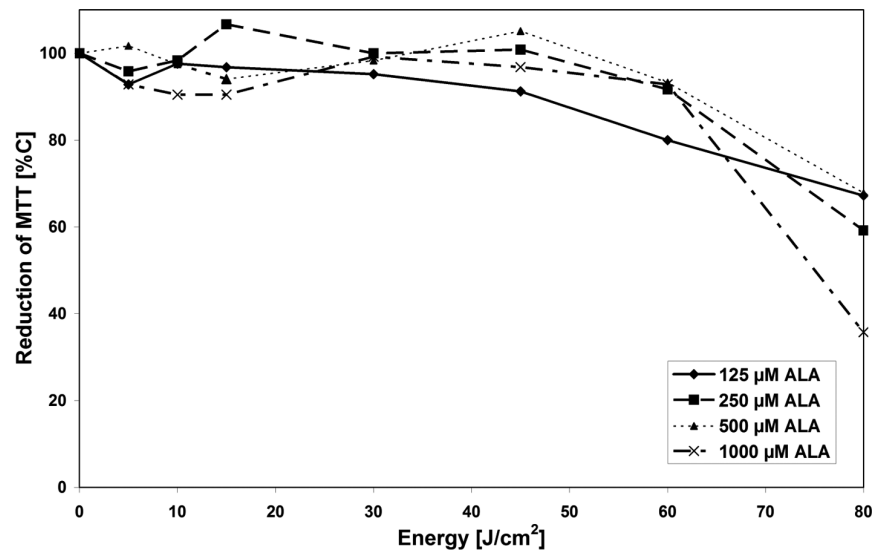

Figure 1. J-774A.1 cell viability using MTT test after LPS stimulation post PDT in different power density and different ALA concentration. Results are presented as a percentage of control group $(\mathrm{p}<0.05)$.

$\mathrm{ml}$ Escherichia coli O111:B4 fetal bovine serum (FBS; Fluka, Buchs) for $18 \mathrm{~h}$. The effects of ALA-PDT were assayed by measuring cell viability and the production of $\mathrm{NO}$ and various cytokines after exposure.

Cell viability. Cell viability was estimated using 3-(4,5dimethylthiazol-2-yl)-2,5-diphenyltetrazolium bromide (MTT) metabolism as previously described (14) and lactate dehydrogenase (LDH) leakage (Roche Diagnostics $\mathrm{GmbH}$ Cytotoxicity Detection Kit).

$N F-\kappa B$ p50/p65. A total of $10^{6}$ cells $/ \mathrm{ml} /$ well of J-774A.1 cells were seeded in a four-well plate (Nunc, $\mathrm{GmbH} \& \mathrm{Co}$. KG). After $3 \mathrm{~h}$, the wells were washed with medium, medium with levulic acid $(250 \mu \mathrm{M})$ was added, and the cells were cultured for $4 \mathrm{~h}$. Next, the medium was changed to medium without ALA, and the cells were exposed to light at $5 \mathrm{~J}$ or $10 \mathrm{~J}$. The source of light was the incoherent light source PDT TP-1. The control cells were incubated in the dark at the same temperature as the treated cells.

Stimulation of the cells. After exposure, the medium was removed, and medium with $200 \mathrm{ng} / \mathrm{ml}$ LPS was added for $1 \mathrm{~h}$.

Extraction of nuclear proteins. The extraction procedure was performed using the Nuclear Extraction Kit from the Non-Radioactive Universal EZ-TFA transcription factor assay (Chemicon International Inc., Temecula, CA, USA).

Determination of $N F-\kappa B$ p50/p65 in nuclear extracts. The Non-Radioactive NF-kB p50/p65 Transcription Factor Assay Kit (Chemicon International Inc.) was used to determine the levels of activated NF- $\mathrm{KB}$ p50/p65 in nuclear extracts.

The capture probe, a double-stranded biotinylated oligonucleotide containing the consensus sequence for NF- $\mathrm{\kappa B}$ binding (5'-GGGACTTTCC-3') was mixed with nuclear extracts. Next, the extract/probe/buffer mixture was transferred to a streptavidin-coated plate. The bound NF- $\mathrm{KB}$ transcription factor subunits $\mathrm{p} 50$ and p65 were detected with specific primary rabbit antibodies. An HRP-conjugated secondary antibody was used for detection and provided sensitive colo- 


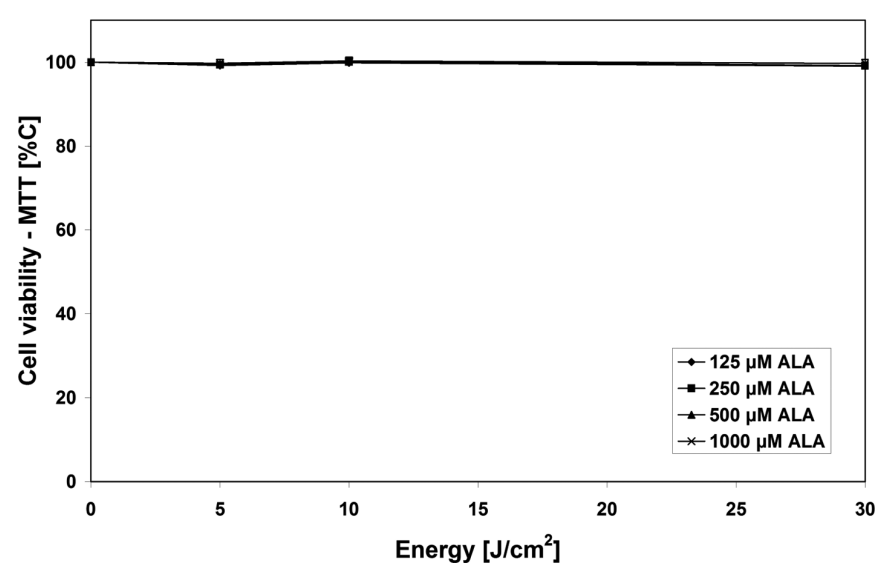

Figure 2. J-774A.1 cell viability using MTT test after LPS stimulation post PDT in following power density: $5,10,30 \mathrm{~J} / \mathrm{cm}^{2}$ at different ALA concentration. Results are presented as a percentage of control group $(\mathrm{p}<0.05)$.

rimetric detection using the Elx 800 spectrophotometric plate reader (BioTek Instruments Inc., Winooski, VT, USA).

The amount of nuclear extracts was $5 \mu \mathrm{g}$ protein/ well. Positive cell extracts, a non-specific double-stranded oligonucleotide, and a specific competitor double-stranded oligonucleotide were used as controls.

Cytokine concentrations. The concentration of IL-1 $\beta$ and TNF- $\alpha$ in the supernatants of the cell culture was measured using Quantikine Colorimetric Sandwich ELISAs (enzymelinked immunosorbent assay) (R\&D, Minneapolis, MN, USA). All of the reagents were prepared according to the manufacturer's protocol. Supernatant samples and standards were added to each well in equal volumes. After $2 \mathrm{~h}$ of incubation at room temperature, each well was aspirated and wells were washed three times using wash buffer. Then, equal volumes of antibody conjugated to horseradish peroxidase were added to each well and incubated for $2 \mathrm{~h}$ (for IL-1 $\beta$, this second incubation was for $1 \mathrm{~h}$ ). The wells were aspirated and washed 3 times. Then, the substrate solution was added to each well. After $20 \mathrm{~min}$ of incubation, the stop solution was added to all wells, and the optical density of each well at $450 \mathrm{~nm}$ was determined using the Elx 800 microplate reader. Results were calculated using standard curves.

NO concentration. The nitrite concentration in the culture medium was measured using a microplate assay method based on the Griess reaction. Equal volumes of culture medium supernatant and Griess reagent $(0.5 \%$ sulfanilamide and $0.05 \%$ naphthylene-diamide dihydrochloride in $2.5 \%$ orthophosphoric acid $\mathrm{H}_{3} \mathrm{PO}_{4}$ ) were added to a microplate and incubated at $25^{\circ} \mathrm{C}$ for $10 \mathrm{~min}$. The absorbance of the culture medium and Griess reagent at $550 \mathrm{~nm}$ was determined using the ELX 800 microplate reader. Sodium nitrite was used as the standard (15).

Chemiluminescence. The chemiluminescence of J-774A.1 cells was measured after stimulation with phorbol myristate acetate (PMA, Sigma, St. Louis, MO, USA), which was added $5 \mathrm{~min}$ after the application of luminol, and recorded in a system equipped with a photomultiplier (9514s, EMI, Middlesex,

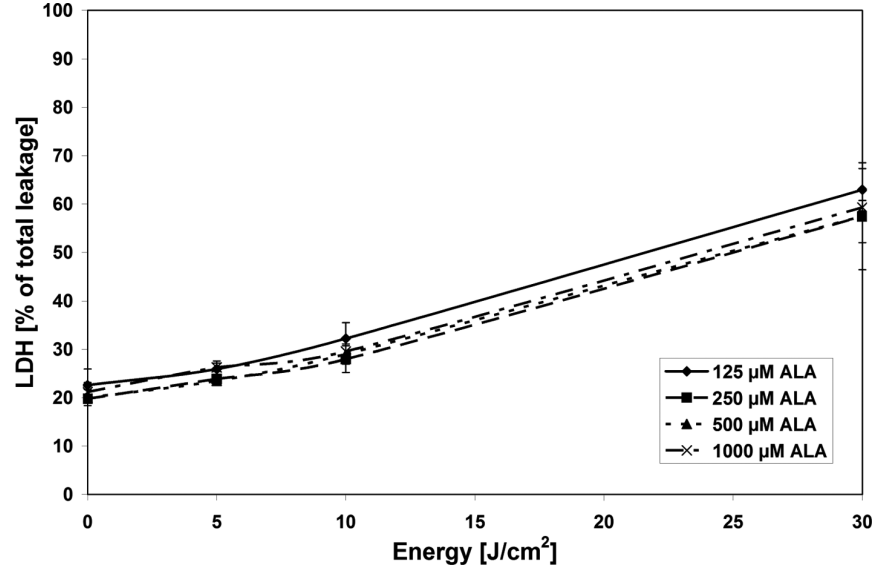

Figure 3. Release of LDH of J-774A.1 after LPS stimulation post PDT in different ALA concentration. Results are presented as a percentage of control group $(\mathrm{p}<0.05)$.

UK). The sample volume was $1 \mathrm{ml}$. The following reagents were added to the cell culture $\left(10^{6}\right.$ cell $\left./ \mathrm{ml}\right): 1.13 \times 10^{-4} \mathrm{M}$ luminol, $8 \times 10^{-7}$ M PMA and Hanks buffer, pH 7.4 (Gibco, Paisley, Scotland). Chemiluminescence measurements were performed using the technique of single photon counting continuously for $15 \mathrm{~min}$ (16).

Statistical analysis. Statistical methods comprised mean, standard deviation (SD), standard error of mean (SEM), median, lower and upper quartile. T-test was performed for dependent samples to compare the parameters to control. $\mathrm{p}<0.05$ was considered statistically significant.

\section{Results}

Cell viability at different doses of energy with different concentrations of ALA was assessed (Fig. 1). On the basis of these results, further experiments were performed at 5 , 10 and $30 \mathrm{~J} / \mathrm{cm}^{2}$ with different concentrations of ALA (125, $250,500$, and $1000 \mu \mathrm{M})$. Results of cell viability, measured using MTT test at 5, 10 and $30 \mathrm{~J} / \mathrm{cm}^{2}$ (Fig. 2), was confirmed by the LDH leakage from dead cells. The release of LDH by the cells increased dose-dependently; at lower doses of energy LDH levels were not significant initially, but they were higher at $30 \mathrm{~J} / \mathrm{cm}^{2}$ (Fig. 3). Cell survival following PDT decreased gradually with increasing doses of light. At 5 and $10 \mathrm{~J} / \mathrm{cm}^{2}$, the cell viability was comparable with the control group. Therefore, the next investigations were performed at these doses of energy, using different concentrations of ALA. TNF- $\alpha$ release was amplified at $10 \mathrm{~J} / \mathrm{cm}^{2}$. At $30 \mathrm{~J} / \mathrm{cm}^{2}$ energy doses, the concentration of TNF- $\alpha$ was decreased, which was probably due to the cytotoxic influence of higher irradiation (Fig. 4). Next experiment revealed, that ALA PDT leads to attenuation of the level of NF- $\mathrm{BB}$ p50 (Fig. 5)/p65 (Fig. 6) and reduction of the level of IL-1 $\beta$ (Fig. 7).

Subsequently research revealed, that the greatest increase in chemiluminescence was at $10 \mathrm{~J} / \mathrm{cm}^{2}$, with following diminution at $30 \mathrm{~J} / \mathrm{cm}^{2}$ (Fig. 8). At these doses of energy, using different concentrations of ALA, we observed that the higher the energy doses, the greater the observed decrease of NO release was (Fig. 9). 


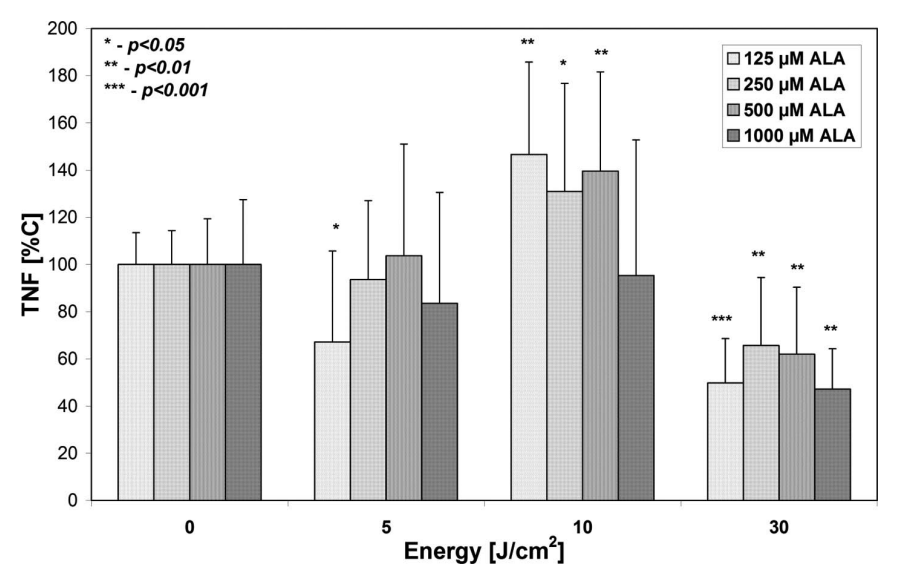

Figure 4. Release of TNF- $\alpha$ from J-774A.1 cells after LPS stimulation post PDT in different ALA concentration. Results are presented as a percentage of control group $(\mathrm{p}<0.05)$.

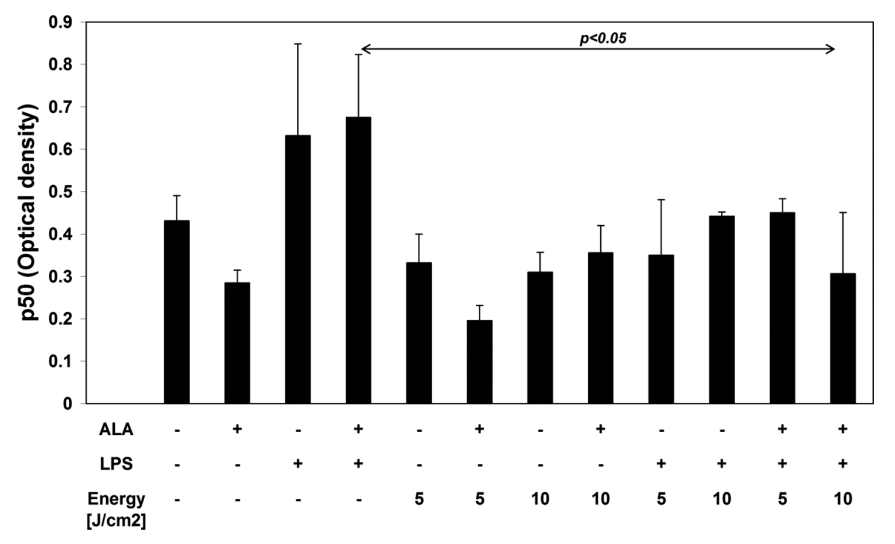

Figure 5. Level of p50 of J-774A.1 after LPS stimulation post PDT. Results are presented as a percentage of control group $(\mathrm{p}<0.05)$.

The secretory activity of the cells was also found to be dependent on the ALA concentration. Strong secretory activity was found at $500 \mu \mathrm{M}$.

\section{Discussion}

The differences in the nature and intensity of the inflammatory reaction between normal and cancerous tissues are still unknown. In addition, the influence of PDT on the angiogenesis and invasiveness of tumor cells and tumor growth requires further investigation. Therefore, elucidation of the participation of the immune response in PDT is essential to recognize the mechanisms of PDT action.

Inflammation seems to be an important tumor promoter, and some cytokines, such as IL-1, IL-6 and TNF, can promote tumor growth, invasion and metastasis. Similar findings to our results have been reported by other authors using in vitro studies. PDT has been shown to stimulate macrophages, neutrophils and $\mathrm{T}$ lymphocytes to secrete cytokines, such as IL-6, IL-10, and TNF- $\alpha$ (17).

In PDT-treated EM6 tumors in the BALB/c mouse model, IL-6 mRNA and protein levels were strongly enhanced and IL-10 was markedly induced, but no changes in TNF- $\alpha$ were observed (18). In addition, a clinical study demonstrated

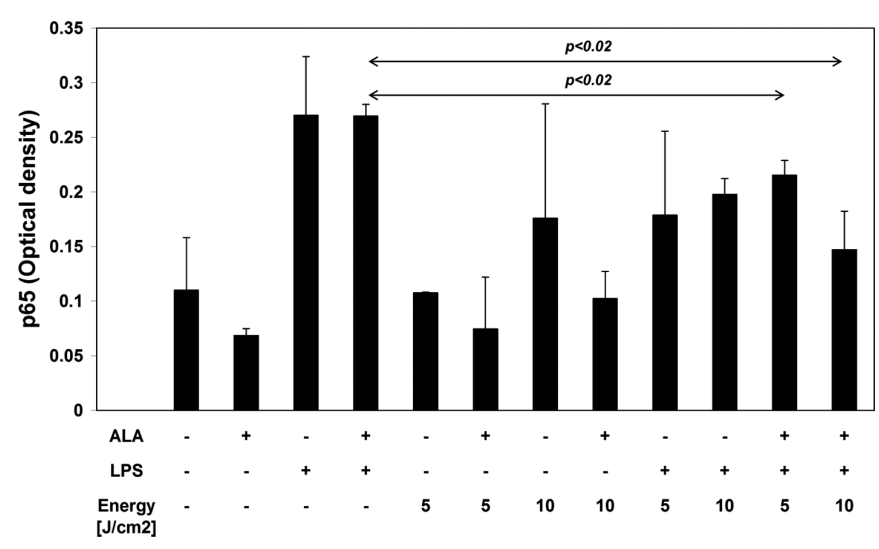

Figure 6. Level of p65 of J-774A.1 after LPS stimulation post PDT. Results are presented as a percentage of control group $(\mathrm{p}<0.02) ; \mathrm{n}=4$.

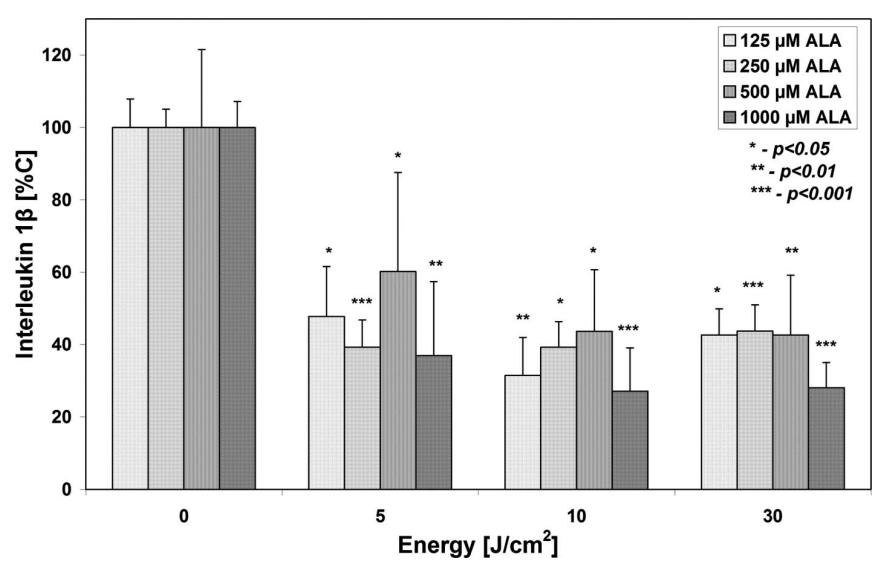

Figure 7. Release of IL-1 $\beta$ from J-774A.1 cells after LPS stimulation post PDT in different ALA concentration. Results are presented as a percentage of control group $(\mathrm{p}<0.05)$.

that PDT had immunomodulating activity in malignant skin tumors and oral leukoplakia (19).

$\mathrm{NF}-\kappa \mathrm{B}$ signalling might also be crucial in tumor progression. Several NF- $\kappa \mathrm{B}$-regulated genes that encode adhesion molecules, serine proteases and chemokines were shown to be essential for tumor invasion and metastasis. Our experiment reveal, that ALA PDT leads to attenuation of the level of $\mathrm{NF}-\kappa \mathrm{B}$ p50/p65 and reduction of the level of IL-1 $\beta$.

The adhesion of circulating cancer cells to capillary endothelia is a critical step in the initiation of metastasis. Vidal-Vanaclocha reported results demonstrating a role for IL-1 $\beta$ and IL-18 in the development of hepatic metastases of melanoma in vivo (20). In vitro, soluble products from mouse melanoma cells stimulated the hepatic sinusoidal endothelium to sequentially release of TNF- $\alpha$, IL-1 $1 \beta$, and IL- 18 .

Baek et al demonstrated that IL-1 $\beta$ caused nuclear export of a specific NCOR corepressor complex, resulting in a decrease in a specific subset of NF- $\mathrm{BB}$-regulated genes (21).

Voronov et al showed that microenvironmental IL1- $\beta$ and, to a lesser extent, IL1- $\alpha$ were required for in vivo angiogenesis and the invasiveness of different tumor cells (22). Furthermore, they reported anti-angiogenic effects of IL1RN, suggesting a possible therapeutic role in cancer in addition to its use in rheumatoid arthritis. 


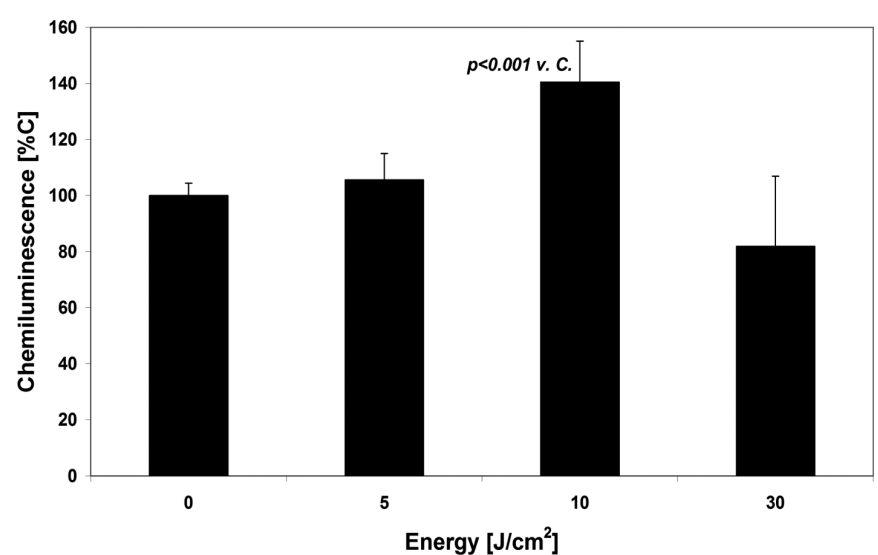

Figure 8. Chemiluminescence of J-774A.1 after LPS stimulation post PDT. Results are presented as a percentage of control group $(\mathrm{p}<0.05)$.

Our results are comparable with some findings that have demonstrated the capacity of PDT to cause a significant suppression of IL- $1 \beta$ production. The observations of de Vree (23) suggest that the effect of PDT on rat rabdomyosarcoma tumor growth is connected with elevated serum levels of IL-1 $\beta$, yielding an increase in the number of functionally activated mature neutrophils as a nonspecific immune reaction to the tumor. PDT has been reported to inhibit this cytokine secretion of peripheral mononuclear cells isolated from patients suffering from psoriasis (24). In another study, a light energy-dependent production of TNF- $\alpha$ and a fluence-dependent increase in nitric oxide by photosensitized (meso-tetrahydroxyphenylchlorin -mTHPC) macrophages were noted (17).

TNF- $\alpha$ is a cytokine responsible for a diverse range of signaling events within cells. Actions of TNF- $\alpha$ are mediated by its binding to the specific TNF- $\alpha$ receptors 1 and 2 (TNFR-1 and TNFR-2). The interaction of TNF with TNF receptor-1 (TNF-R1) activates a few signal transduction pathways (25). One pathway stimulates apoptosis via interaction with the TNF- $\alpha$ receptor complex and the Fas-ass associated protein with the death domain.

The second is a mitogen-activated protein kinase (MAPK) pathway, and the third trail is connected with a primary mediator of transcriptional control, activation of $N F-\kappa B$. We observed an increase in $\mathrm{TNF}-\alpha$ release at $10 \mathrm{~J} / \mathrm{cm}^{2}$ and a decrease in TNF- $\alpha$ release at $30 \mathrm{~J} / \mathrm{cm}^{2}$, which was probably associated with the cytotoxic influence of higher irradiation. This cytotoxicity was also associated with a higher leakage of LDH at $30 \mathrm{~J} / \mathrm{cm}^{2}$. Another study showed the induction of IL-1 $\beta$, IL- 6 and TNF- $\alpha$ release in response to photodynamic treatment, apparently intensifying inflammation in the antitumor response (26).

NO plays a dual role in damaging DNA. Auto-oxidation of NO leads to nitrosating species, which cause deamination of bases (27). The reaction of $\mathrm{NO}$ with $\mathrm{O}_{2}$ leads to oxidative DNA damage due to the formation of peroxynitrite, which may have $\mathrm{HO}$-like oxidizing potential. Another possible mechanism of oxidative damage by NO could be the mobilization of free iron by NO, which could ultimately cause Fenton-type reactions. Therefore, nitric oxide not only leads to deamination of DNA bases but is also an obligatory factor in oxidative damage to

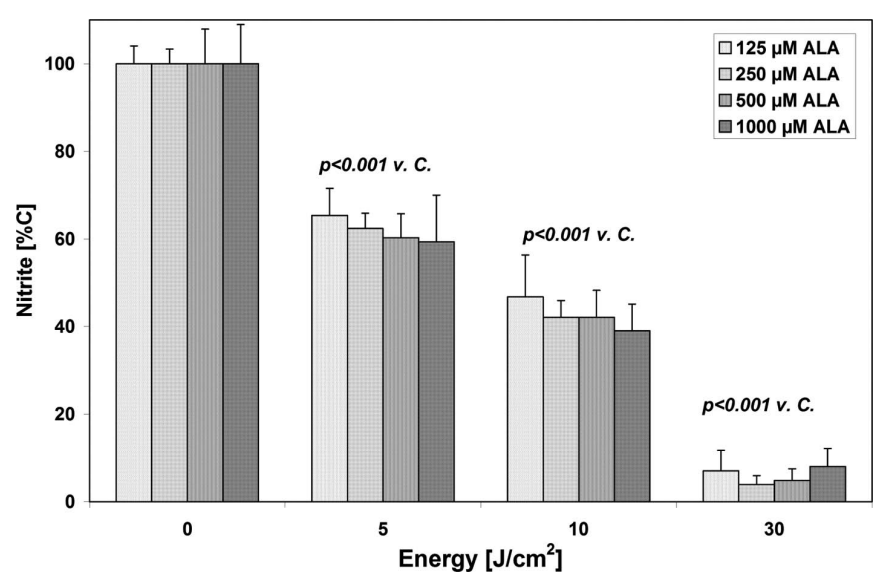

Figure 9. Release of NO of J-774A.1 after LPS stimulation post PDT in different ALA concentration. Results are presented as a percentage of control group $(\mathrm{p}<0.05)$.

DNA (28). Our experiments revealed a decrease in NO release. Previous results have shown that NO decreases the extent of apoptotic cell death after PDT treatment through a protein kinase $\mathrm{G}$ (PKG)-dependent mechanism upstream or at the level of caspase activation (28).

It has been demonstrated that PDT stimulates the host immune system (29). In contrast to surgery, radiotherapy and chemotherapy, which are mostly immunosuppressive, PDT causes acute inflammation, the expression of heat-shock proteins, invasion and infiltration of the tumor by leukocytes, and might increase the presentation of tumor-derived antigens to $\mathrm{T}$ cells. It seems that PDT also has a crucial role in angiogenesis and the invasiveness of tumor cells. Oseroff showed that PDT acts as a biological response modifier in addition to directly damaging target cells and their blood supply (30). The increase in the intensity of the chemiluminescence may be the result of pre-activation of cells, known as priming. One of the essential priming stimulating agents is TNF- $\alpha$, which induces human neutrophil cytotoxic activity against malignant cells. An enhancement of phagocytosis and respiratory burst and an increase in the expression of integrin receptors occurs in human polymorphonuclear cells after TNF- $\alpha$ stimulation.

Macrophages promote cancer metastasis through promotion of angiogenesis, induction of tumor growth, and enhancement of tumor cell migration and invasion. Clinical studies have shown a correlation between the numbers of TAMs and poor prognosis for some cancers (breast, prostate, ovarian, cervical, endometrial, esophageal and bladder) (31-35). TAMs are also associated with increased angiogenesis or lymph node metastasis in cancer tissues. Since PDT not only reduces the tumor burden but also influence on immune cells and inflammation, it has been suggested that the recruitment of activated macrophages to inflammatory tumor lesions is the major factor for the complete eradication of tumors and major factor of enhancement of tumor cell invasion and metastasis.

Cancer stimulates macrophage infiltration, but PDT is an immunomodulator due to modulation of secretory activity of macrophages. This additional event that occur during PDT that leads to and magnifies the inactivation of tumor cells and simultaneously diminished factors responsible for tumor 
growth and invasion. Activity and the control of TAMs to be pro-metastatic or tumoricidal is an important subject for cancer therapy.

Our study presents the effect of PDT on macrophageinduced anti-tumor immune response, and the role of PDT in stimulating and suppressing immune response. The elucidation of the whole mechanism by which PDT kills cancer cells, and its influence on cancer cell angiogenesis, invasiveness and metastatic potential will play a crucial role in clinical indications and guarantees safety of this method of cancer treatment and may help in the design of novel adjunctive cancer therapy in the future (36).

\section{References}

1. Polverini PJ, Cotran RS, Gimbron MA Jr and Unanue ER: Actirated macrophages induce vascular proliferation. Nature 269: 804-806, 1977.

2. Dougherty TJ: A brief history of clinical photodynamic therapy development at Roswell Park Cancer Institute. J Clin Laser Med Surg 14: 219-221, 1996.

3. Tyrrell JS, Campbell SM and Curnow A: The relationship between protoporphyrin IX photobleaching during real-time dermatological methyl-aminolevulinate photodynamic therapy (MAL-PDT) and subsequent clinical outcome. Lasers Surg Med 42: 613-619, 2010.

4. Castano AP, Mroz P and Hamblin MR: Photodynamic therapy and anti-tumour immunity. Nat Rev Cancer 6: 535-545, 2006.

5. Normann SJ: Macrophage infiltration and tumor progression. Cancer Metastasis Rev 4: 277-291, 1985.

6. Gollnick SO, Evans SS, Baumann H, Owczarczak B, Maier PL, Vaughan WC, Wang E, Unger E and Henderson BW: Role of cytokines in photodynamic therapy-induced local and systemic inflammation. Br J Cancer 88: 1772-1779, 2003.

7. Reeves KJ, Reed MW and Brown NJ: The role of nitric oxide in the treatment of tumours with aminolaevulinic acid-induced photodynamic therapy. J Photochem Photobiol B 101: 224-232, 2010.

8. Halliwell B and Cross CE: Oxygen-derived species: their relation to human disease and environmental stress. Environ Health Perspect 102: 5-12, 1994.

9. Dias Ribeiro AP, Pavarina AC, Trindade FZ, Inada NM, Bagnato VS and de Souza Costa CA: Photodynamic therapy associating Photogem ${ }^{\circledR}$ and blue LED on L929 and MDPC-23. Cell Biol Int 34: 343-351, 2010

10. Park JH, Moon YH, Bang IS, Kim YC, Kim SA, Ahn SG and Yoon JH: Antimicrobial effect of photodynamic therapy using a highly pure chlorin e6. Lasers Med Sci 25: 705-710, 2010.

11. Dai T, Huang YY and Hamblin MR: Photodynamic therapy for localized infections - state of the art. Photodiagnosis Photodyn Ther 6: 170-188, 2009.

12. Huang L, Dai T and Hamblin MR: Antimicrobial photodynamic inactivation and photodynamic therapy for infections. Methods Mol Biol 635: 155-173, 2010.

13. Malik R, Manocha A and Suresh DK: Photodynamic therapy - A strategic review. Indian J Dent Res 21: 285-291, 2010.

14. Mosmann T: Rapid colorimetric assay for cellular growth and survival: application to proliferation and cytotoxicity assays. J Immunol Methods 65: 55-63, 1983.

15. Green LC, Wagner DA, Glogowski J, Skipper PL, Wishnok JS and Tannenbaum SR: Analysis of nitrate, nitrite, and $\left({ }^{15} \mathrm{~N}\right)$ nitrate in biological fluids. Anal Biochem 126: 131-138, 1982.

16. Czuba ZP, Król W, Hasiński P and Nowowiejska A: The effects of taxol (paclitaxel) on chemiluminescence of neutrophils, macrophages and J774.2 cell line. Acta Biochim Pol 45: 103-106, 1998.

17. Coutier SL, Bezdetnaya S, Marchal V, Melnikova I, Belitchenko J, Merlin L and Guillemin F: Foscan (mTHPC) photosensitized macrophage activation: en hancement of phagocytosis, nitric oxide release and TNF- $\alpha$ mediated cytolytic activity. Br J Cancer 81: 37-42, 1999.
18. Gollnik SO, Liu X, Owczarczak B, Musser DA and Henderson BW: Altered expression of interleukin 6 and interleukin 10 as a result of photodynamic therapy in vivo. Cancer Res 57: 3904-3909, 1997.

19. Kawczyk-Krupka A, Wiczkowski A, Adamek M and Sieron A: Photodynamic therapy and its immunomodulating activity in malignant skin tumors and oral leukoplakia. Acta Bio-Opt Inf Med 7: 67-72, 2001.

20. Vidal-Vanaclocha F, Fantuzzi G, Mendoza L, Fuentes AM, Anasagasti MJ, Martin J, Carrascal T, Walsh P, Reznikov LL, Novick D, Rubinstein M and Dinarello CA: IL-18 regulates IL-1-beta-dependent hepatic melanoma metastasis via vascular cell adhesion molecule. Proc Natl Acad Sci USA 97: 734-739, 2000.

21. Baek SH, Ohgi KA, Rose DW, Koo EH, Glass CK and Rosenfeld MG: Exchange of N-CoR corepressor and Tip60 coactivator complexes links gene expression by NF-kappa-B and beta-amyloid precursor protein. Cell 110: 55-67, 2002.

22. Voronov E, Shouval DS, Krelin Y, Cagnano E, Benharroch D, Iwakura Y, Dinarello CA and Apte RN: IL-1 is required for tumor invasiveness and angiogenesis. Proc Natl Acad Sci USA 100: 2645-2650, 2003.

23. De Vree, WJ, Essers MC, Koster JF and Sluiter W: Role of interleukin 1 and granulocyte colony-stimulating factor in photofrin-based photodynamic therapy of rat rhabdomyosarcoma tumors. Cancer Res 57: 2555-2558, 1997.

24. Boehncke WH, Konig K, Kaufmann R, Scheffold W, Prummer O and Sterry W: Photodynamic therapy in psoriasis: suppression of cytokine production in vitro and recording of fluorescence modification during treatment in vivo. Arch Dermatol Res 286: 300-303, 1994.

25. Chen G and Goeddel DV: TNF-R1 signaling: a beautiful pathway. Science 296: 1634-1635, 2002.

26. Kick G, Messer G, Plewig G, Kind P and Goetz AE: Strong and prolonged induction of c-jun and c-fos protooncogenes by photodynamic therapy. Br J Cancer 74: 30-36, 1996.

27. De Rojas-Walker T, Tamir S, Ji H, Wishnok JS and Tannenbaum SR: Nitric oxide induces oxidative damage in addition to deamination in macrophage DNA. Chem Res Toxicol 8: 473-477, 1995.

28. Gomes ER, Almeida RD, Carvalho AP and Duarte CB: Nitric oxide modulates tumor cell death induced by photodynamic therapy through a cGMP-dependent mechanism. Photochem Photobiol 76: 423-430, 2002.

29. Castano AP, Mroz P and Hamblin MR: Photodynamic therapy and anti-tumour immunity. Nat Rev Cancer 6: 535-545, 2006.

30. Oseroff A: PDT as a cytotoxic agent and biological response modifier: Implications for cancer prevention and treatment in immunosuppressed and immunocompetent patients. J Invest Dermatol 126: 542-544, 2006.

31. Koide N, Nishio A, Sato T, Sugiyama A and Miyagawa S: Significance of macrophage chemoattractant protein-1 expression and macrophage infiltration in squamous cell carcinoma of the esophagus. Am J Gastroenterol 99: 1667-1674, 2004.

32. Hanada T, Nakagawa M, Emoto A, Nomura T, Nasu N and Nomura Y: Prognostic value of tumor-associated macrophage count in human bladder cancer. Int J Urol 7: 263-269, 2000.

33. Lissbrant IF, Stattin P, Wikstrom P, Damber JE, Egevad L and Bergh A: Tumor associated macrophages in human prostate cancer: Relation to clinicopathological variables and survival. Int J Oncol 17: 445-451, 2000.

34. Ohno S, Ohno Y, Suzuki N, Kamei T, Koike K, Inagawa H, Kohchi C, Soma G and Inoue M: Correlation of histological localization of tumor-associated macrophages with clinicopathological features in endometrial cancer. Anticancer Res 24: 3335-3342, 2004.

35. Leek RD, Landers RJ, Harris AL and Lewis CE: Necrosis correlates with high vascular density and focal macrophage infiltration in invasive carcinoma of the breast. Br J Cancer 79: 991-995, 1999.

36. Casas A, di Venosa G, Vanzulli S, Perotti C, Mamome L, Rodriguez L, Simian M, Juarranz A, Pontiggia O, Hassan T and Battle A: Decreased metastatic phenotype in cells resistant to aminolevulinic acid-photodynamic therapy. Cancer Lett 271: 342-351, 2008. 